\title{
Prevalence of Lower Urinary Tract Symptoms in Austrian Males: Update 2009
}

\author{
Gerald Haidinger $^{\mathrm{a}}$ Thomas Waldhör $^{\mathrm{a}}$ Stephan Madersbacher ${ }^{\mathrm{c}}$ Georg Schatzl ${ }^{\mathrm{b}}$ \\ Christian Vutuc ${ }^{\mathrm{a}}$ \\ Departments of a Epidemiology, Center of Public Health, and ${ }^{b}$ Urology, Medical University of Vienna, and \\ 'Department of Urology, Donauspital, Vienna, Austria
}

\section{Key Words}

Urinary tract $\cdot$ Urologic diseases $\cdot$ Austria

\begin{abstract}
Introduction: The prevalence of lower urinary tract symptoms (LUTS) in a representative sample of Austrian males aged 15-89 years was assessed in 2009. The results were compared with the findings of a similar study conducted in 1995. Materials and Methods: A population-based crosssectional survey on LUTS was conducted in 2009 in Austria. A quota sample of 1,926 Austrians was selected. The sample comprised $0.03 \%$ of the population and was representative in terms of age, sex, occupational status and area of residence. Results: Some degree of LUTS is reported by $64.6 \%$ of the male population in Austria aged 15-89 years. IPSS correlates significantly with age. In all age groups storage symptoms are more prevalent than voiding symptoms. The prevalence of voiding symptoms (IPSS $>0$ ) among Austrian males is $35.5 \%$ and the prevalence of storage symptoms is $61.6 \%$. In both groups the prevalence increases with age. Compared to 1995 , the prevalence of dissatisfaction declined significantly. An extrapolated number of more than 35,000 men are 'terribly' dissatisfied with their current urinary condition.
\end{abstract}

Conclusions: The prevalence of LUTS in Austria meliorated in Austria significantly between 1995 and 2009. This in part may be attributed to intensified contact of males with urologists in the past.

Copyright ๑ 2011 S. Karger AG, Basel

\section{Introduction}

The treatment of men with lower urinary tract symptoms (LUTS) has received much attention due to evidence that this condition is much more common than previously estimated and because new forms of treatment are emerging. In 1999 we reported on the prevalence of LUTS in a representative survey of Austrian males and its associations with socio-demographic variables [1]. We concluded that in 1995 about $12 \%$ of the males aged $40-89$ years are dissatisfied with urinary symptoms, giving a number of more than 87,000 men who would feel 'terribly' if they were to spend the rest of their lives with urinary symptoms as they were at the time of the survey. In this paper we present an update, a representative survey performed in 2009, based on the same questionnaire. We hypothesized that between 1995 and 2009 due to an enor-

\section{KARGER}

Fax +4161306 1234 E-Mail karger@karger.ch www.karger.com

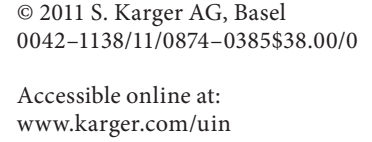

Gerald Haidinger, MD

Department of Epidemiology, Center of Public Health, Medical University of Vienna Borschkegasse 8 a

AT-1090 Vienna (Austria)

Tel. +43 1427765 183, E-Mail gerald.haidinger@meduniwien.ac.at 
mous increase in testing for prostate-specific antigen (PSA) [2-5] and hence intensified contacts between patients and urologists, an impact on the prevalence of LUTS can be expected.

\section{Methods}

The data for this study were extracted from a populationbased cross-sectional survey on knowledge and attitudes towards LUTS, conducted in October and November 2009, which covered all parts of Austria (population: 8.34 million, 7.07 million $\geq 15$ years of age) [6]. In cooperation with a public opinion survey institute a quota sample of 1,926 Austrians aged 15 years and over was randomly selected. The quota sample comprised $0.03 \%$ of the population $\geq 15$ years of age, and was representative in terms of age, sex, occupational status, and area of residence (source: Population Census 2001). The respondents were visited in their homes by trained interviewers. The interviews were face to face, using an anonymous standardized questionnaire. Of the 2,000 planned interviews a quota of $96.3 \%$ was completed; 74 persons were not at home or refused an interview. The remaining sample of 1,926 persons (930 men and 996 women) met the inclusion criteria with respect to representativeness in terms of age, sex, occupational status, and area of residence. The sample of the current analysis consists of 930 males aged 15-89 years. LUTS and the degree of complaints were assessed by using the International Prostate Symptom Score (IPSS) in the form of a self-administered questionnaire. The results from question 8 (quality of life) are analyzed separately. Due to the non-normal distribution of IPSS within most age groups (except age groups $70-79$ and $80-89$ years; tested by using the KolmogoroffSmirnoff test), analyses and presentation of results are confined to using medians.

Following AUA scoring conventions [7], we grouped scores into 'mild' (AUA score 0-7), and 'moderate to severe' (score 8+) categories. The symptoms 'straining', 'incomplete emptying', 'intermittency' and 'weak stream' are summarized into the group 'voiding symptoms'; the symptoms 'frequency', 'urgency' and 'nocturia' into the group 'storage symptoms'. Age was categorized into age groups $15-29,30-39,40-49,50-59,60-69,70-79$ and $80-89$ years. Monthly household income was grouped into tertiles (EUR 1-1,600, EUR 1,601-2,545 and EUR 2,546 or more). Differences in prevalence between groups (mild vs. moderate-tosevere) were tested by using the Kruskal-Wallis as well as $\chi^{2}$ tests. Correlation of IPSS with selected variables was tested by using Spearman's correlation $\left(\mathrm{r}_{\mathrm{s}}\right)$ or Pearson's partial correlation $(\mathrm{r})$, in case of controlling for age. Confidence intervals for the prevalence were calculated on the $95 \%$ level. The extrapolation of the prevalence of bothersomeness from our sample to the Austrian population was done age-adjusted. In 2008 , the male population in Austria within 15-89 years of age comprised 3,408,255 persons, 2,015,155 of them (59.1\%) were aged between 40 and 89 years [8].

The methods for collection of the 1995 data to which the 2009 data are compared are described elsewhere [1]. In short, the same questionnaire was used by the same public opinion institute and was administered to a representative sample of 972 Austrian men.

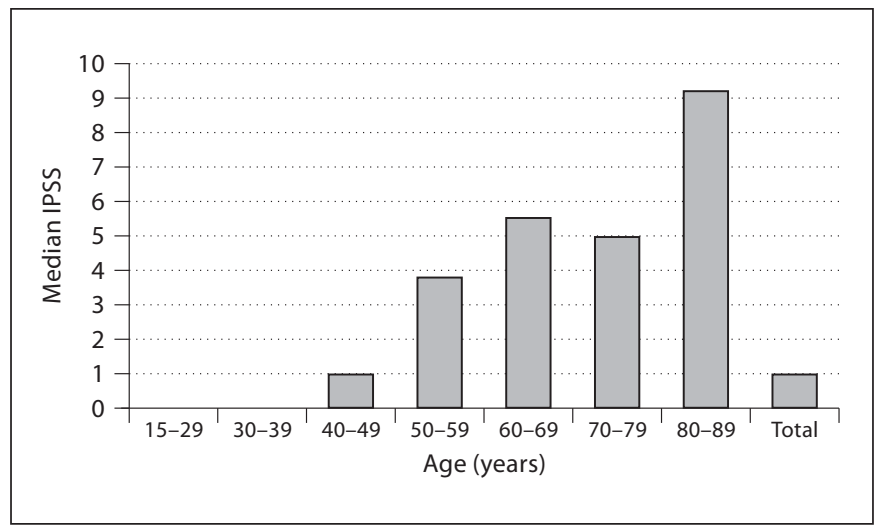

Fig. 1. Median IPSS by age group in a representative sample of Austrian males aged 15-89 years.

\section{Results}

\section{Descriptive Results of the 2009 Survey}

The most prominent result is that $64.6 \%$ of the male population in Austria aged 15-89 years report some degree of LUTS (IPSS from 1 to 32, 14.6\% of all had a score of ' 1 '). No complaints at all (IPSS $=0$ ) are reported by $35.4 \%$ of the respondents. The mean age of those who report symptoms (IPSS $>0$ ) is 47.3 years (standard deviation, SD: 16.4 years), the mean age of males without LUTS is 35.4 years (SD 13.3 years). The frequency of symptoms (as expressed in higher scores) increases with age. The median of the IPSS by age group is presented in figure 1 . The median score for all ages (15-89 years) is 1.0. The lowest median score (0.0) is found in the age groups 15-29 and $30-39$ and the highest (9.2) in the age group $80-89$ years.

After grouping into severity categories, the prevalence of mild symptoms was $85.9 \%$ (including the group of males with no complaints at all: IPSS $=0$ ), the prevalence of moderate-to-severe symptoms is $14.1 \%$ (table 1 ). The prevalence of moderate-to-severe symptoms increases with age, the IPSS score rises from a median of $\leq 1$ for men below age 50 to 3.8 for men in their $50 \mathrm{~s}$, to 5.5 for men aged 60-69 years, 5.0 for men in their 70 s, and 9.2 for men 80 years of age and above.

When subdividing the IPSS into voiding symptoms and storage symptoms, the median score across all age groups is 0 for voiding symptoms and 1 for storage symptoms (fig. 2). In all age groups, storage symptoms are more prevalent than voiding symptoms (table 2). The prevalence of voiding symptoms (IPSS $>0$ ) among Austrian males is $35.5 \%$ and the prevalence of storage symptoms is $61.6 \%$. 
Table 1. Prevalence of LUTS in Austrian males in 2009 and changes versus 1995

\begin{tabular}{|c|c|c|c|c|c|c|c|}
\hline \multirow[t]{2}{*}{ Age group } & \multirow[t]{2}{*}{$\mathrm{n}$} & \multicolumn{3}{|l|}{ Mild } & \multicolumn{3}{|c|}{ Moderate-to-severe } \\
\hline & & $\%$ & $\mathrm{CI}$ & $\begin{array}{l}\% \text { change } \\
\text { to } 1995\end{array}$ & $\%$ & CI & $\begin{array}{l}\% \text { change } \\
\text { to } 1995\end{array}$ \\
\hline Total & 930 & 85.9 & $83.5-88.1$ & +2.8 & 14.1 & $11.9-16.5$ & -2.8 \\
\hline 15-29 years & 215 & 98.1 & $95.3-99.5$ & +4.9 & 1.9 & $0.5-4.7$ & -4.9 \\
\hline 30-39 years & 196 & 93.9 & $89.5-96.8$ & +1.0 & 6.1 & $3.2-10.5$ & -1.0 \\
\hline $40-49$ years & 200 & 90.0 & $85.0-93.8$ & -1.0 & 10.0 & $6.2-15.5$ & +1.0 \\
\hline $50-59$ years & 134 & 76.9 & $68.8-83.7$ & +11.3 & 23.1 & $16.3-31.2$ & -11.3 \\
\hline 60-69 years & 139 & 66.9 & $58.4-74.6$ & +1.0 & 33.1 & $25.4-41.6$ & -1.0 \\
\hline 70-79 years & 39 & 64.1 & $47.2-78.8$ & +6.6 & 35.9 & $21.2-52.1$ & -6.6 \\
\hline 80-89 years & 7 & 42.9 & $9.9-81.6$ & +42.9 & 57.1 & $18.4-90.1$ & -42.9 \\
\hline \multicolumn{8}{|l|}{ Education } \\
\hline Up to 9 years & 169 & 80.5 & $73.7-86.2$ & -2.4 & 19.5 & $13.8-26.3$ & +2.4 \\
\hline$>9$ years & 761 & 87.0 & $84.4-89.3$ & +2.7 & 13.0 & $10.7-15.6$ & -2.4 \\
\hline \multicolumn{8}{|c|}{ Monthly household income } \\
\hline Low & 328 & 79.4 & $74.5-83.5$ & -1.5 & 20.6 & $16.5-25.5$ & +1.5 \\
\hline Medium & 238 & 83.2 & $77.8-87.7$ & -1.6 & 16.8 & $12.3-22.2$ & +1.6 \\
\hline High & 239 & 92.1 & $87.9-95.1$ & +8.3 & 7.9 & $4.9-12.1$ & -8.3 \\
\hline \multicolumn{8}{|l|}{ BMI } \\
\hline$<20$ & 14 & 100 & $76.8-100$ & +18.9 & 0 & $0.0-23.2$ & -18.9 \\
\hline $20-24.9$ & 336 & 90.2 & $86.5-93.5$ & +4.3 & 9.8 & $6.9-13.5$ & -4.3 \\
\hline $25-29.9$ & 328 & 83.8 & $79.4-87.7$ & +3.3 & 16.2 & $12.3-20.6$ & -3.3 \\
\hline$\geq 30$ & 127 & 81.9 & $74.1-88.2$ & +0.3 & 18.1 & $11.8-25.9$ & -0.3 \\
\hline \multicolumn{8}{|l|}{ Smoking status } \\
\hline Never & 344 & 87.2 & $83.2-90.6$ & +2.5 & 12.8 & $9.4-16.8$ & -2.5 \\
\hline Ex-smoker & 187 & 78.1 & $71.5-83.8$ & +5.1 & 21.9 & $16.2-28.5$ & -5.1 \\
\hline Smoker & 378 & 88.1 & $84.4-91.2$ & +3.1 & 11.9 & $8.8-15.6$ & -3.1 \\
\hline \multicolumn{8}{|l|}{ Age $15-39$ years } \\
\hline Never & 149 & 97.3 & $93.3-99.3$ & +2.8 & 2.7 & $0.7-6.7$ & -2.8 \\
\hline Ex-smoker & 46 & 97.8 & $88.5-99.9$ & +11.7 & 2.2 & $0.1-11.5$ & -11.7 \\
\hline Smoker & 202 & 95.0 & $91.1-97.6$ & +2.1 & 5.0 & $2.4-8.9$ & -2.1 \\
\hline \multicolumn{8}{|l|}{ Age $40-89$ years } \\
\hline Never & 195 & 79.5 & $73.1-84.9$ & +6.4 & 20.5 & $15.1-26.9$ & -6.4 \\
\hline Ex-smoker & 137 & 73.0 & $64.7-80.2$ & +4.4 & 27.0 & $19.8-35.3$ & -4.4 \\
\hline Smoker & 177 & 79.7 & $73.0-85.3$ & +5.1 & 20.3 & $14.7-27.0$ & -5.1 \\
\hline
\end{tabular}

Table 2. Prevalence of voiding and storage symptoms in Austrian males, 2009

\begin{tabular}{|c|c|c|c|c|c|c|}
\hline \multirow[t]{2}{*}{ Age group } & \multicolumn{3}{|c|}{ Voiding symptoms } & \multicolumn{3}{|c|}{ Storage symptoms } \\
\hline & $\%$ & $\mathrm{CI}$ & $\begin{array}{l}\% \text { change } \\
\text { to } 1995\end{array}$ & $\%$ & $\mathrm{CI}$ & $\begin{array}{l}\% \text { change } \\
\text { to } 1995\end{array}$ \\
\hline All age groups & 35.5 & $31.4-39.6$ & -9.9 & 61.6 & $56.3-67.0$ & -6.5 \\
\hline $15-29$ years & 19.7 & $9.7-29.9$ & -7.8 & 45.7 & $33.3-57.9$ & -7.5 \\
\hline $30-39$ years & 18.3 & $12.6-23.8$ & -16.0 & 47.2 & $40.8-53.8$ & -13.9 \\
\hline $40-49$ years & 34.0 & $20.4-47.4$ & -9.2 & 64.3 & $47.7-80.8$ & -2.8 \\
\hline $50-59$ years & 50.0 & $40.4-59.7$ & -17.2 & 76.3 & $58.4-94.1$ & -8.1 \\
\hline $60-69$ years & 60.0 & $43.4-76.7$ & -12.0 & 82.8 & $73.7-91.9$ & -5.1 \\
\hline $70-79$ years & 65.9 & $39.2-93.7$ & -1.6 & 82.9 & $68.6-98.5$ & -4.6 \\
\hline $80-89$ years & 87.9 & $68.3-100.0$ & -12.1 & 67.1 & $35.9-97.4$ & -32.9 \\
\hline
\end{tabular}


Table 3. 'If you were to spend the rest of your life with your urinary condition the way it is now, how would you feel about that?' (IPSS question 8, 'quality of life') Austrian males, 2009

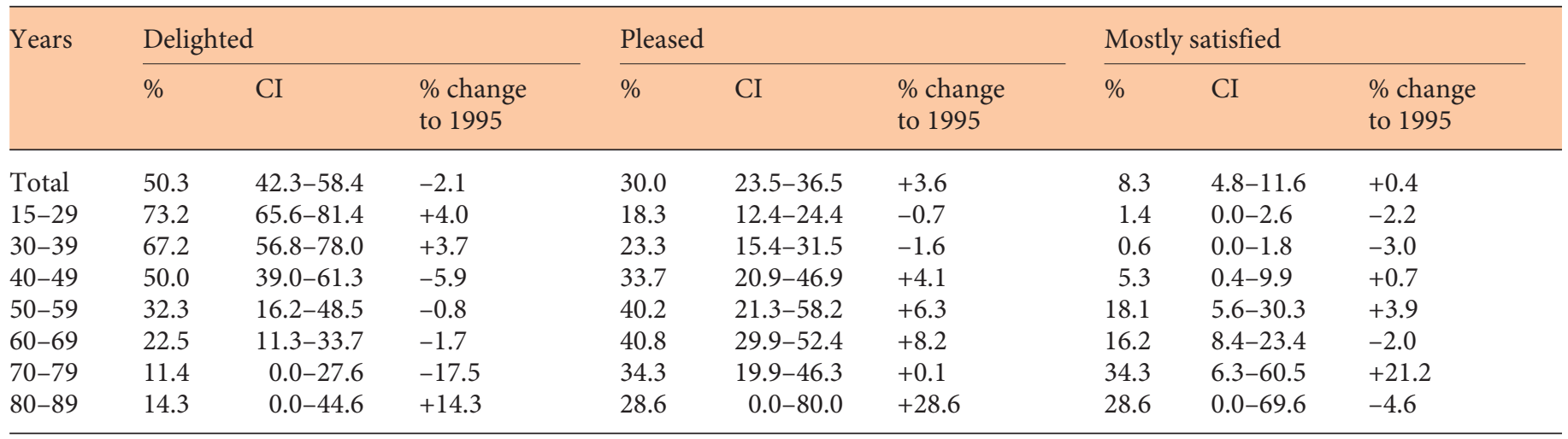

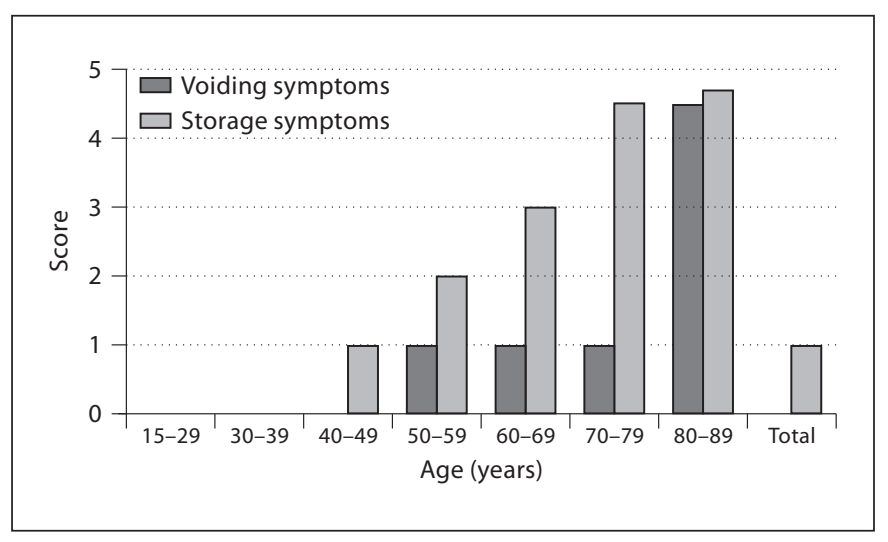

Fig. 2. IPSS medians of voiding and storage symptoms by age group, Austrian males 2009.

\section{Variables Potentially Influencing IPSS}

IPSS correlates significantly with age $\left(\mathrm{p}<0.001, \mathrm{r}_{\mathrm{s}}=\right.$ 0.445 ). While controlling for age, weak but statistically significant negative associations of IPSS with education $(\mathrm{p}=0.004, \mathrm{r}=-0.109)$ and with monthly household income $(p=0.005, r=-0.105)$ were found. No correlation of IPSS was found regarding BMI. With regard to smoking, statistically significant differences between smokers (mean age: 39.7 years) and never-smokers (mean age: 47.0 years, $\mathrm{p}<0.001)$ in IPSS can be found: the IPSS in smokers is 3.29 , whereas that in never-smokers is 4.07 ( $\mathrm{p}=$ 0.002 ). Of smokers, $13.0 \%$ report moderate-to-severe symptoms, while in never-smokers this proportion is $19.3 \%(\mathrm{p}=0.001)$.

After subdividing the IPSS into voiding symptoms and storage symptoms, in both groups the prevalence increases with age (except voiding symptoms in the age group
30-39, which are somewhat below the prevalence of age group 15-29) and storage symptoms which are lowest in the age group 80-89 years. Again, the prevalence also of these subgroups seems to be lower in smokers than in never-smokers: $34.1 \%$ of smokers report voiding symptoms, compared to $39.0 \%$ of never-smokers $(\mathrm{p}=0.026)$. In storage symptoms smokers also report a lower percentage than never-smokers, although statistically nonsignificant. As already mentioned, it has to be noted that the mean age of smokers is about 7 years below that of neversmokers and that age heavily influences prevalence.

\section{Question 8 - Quality of Life}

The prevalence of dissatisfaction increases with age (table 3). After collapsing the scores 4, 5 and 6 ('mostly dissatisfied', 'unhappy' and 'terrible') into one category, it can be shown that $8.0 \%$ of males aged $40-89$ years (compared to $7.4 \%$ of the male population aged $15-89$ years) are at least dissatisfied with urinary function. The extrapolation of this prevalence to the male Austrian population aged 40-89 years results in a total of 153,374 males who are dissatisfied with their current urinary condition, 35,776 of the them 'terribly' (Austrian males 15-89 years: 247,252 persons who are dissatisfied, 56,696 of them 'terribly').

\section{Comparison $2009(n=930)$ versus $1995(n=972)$}

The comparison of the results regarding LUTS (table 4) shows that overall IPSS improved by almost 1 point, from a mean of 5.81 to 4.96 ( $\mathrm{p}=0.033$ ) and from a median of 4.0 to a median of $3.0(p=0.001)$, respectively. The results of each single item meliorated, five of them (incomplete emptying, frequency, intermittency, weak stream, and straining) statistically significantly. 


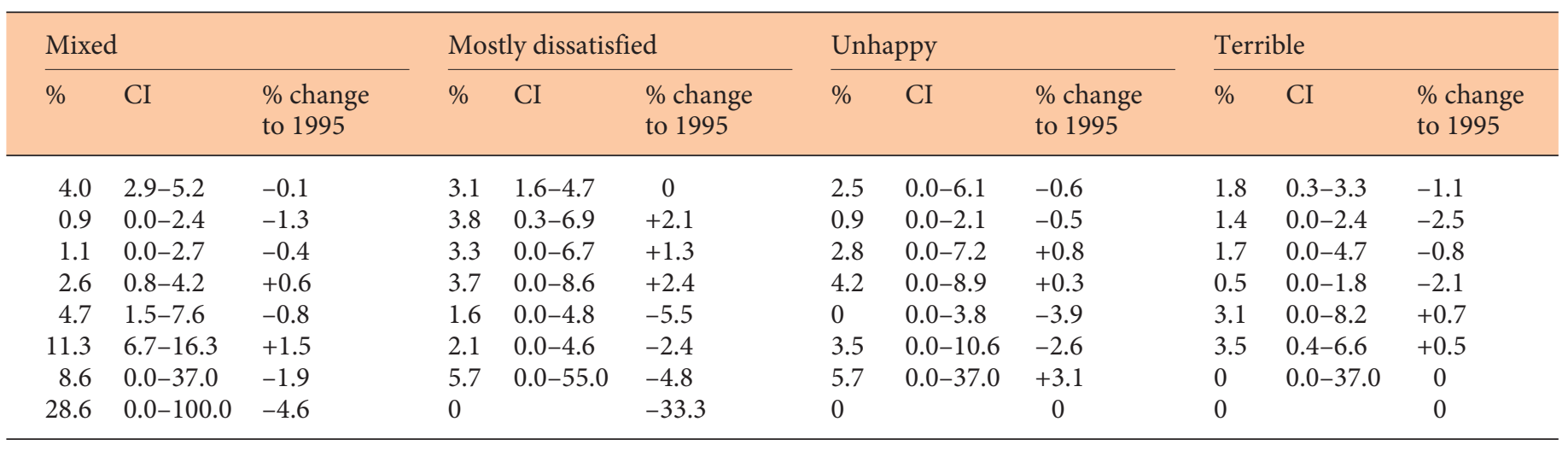

Table 4. Comparison of the results (median IPSS, questions 1-7) in 1995 with the results in 2009 with regard to LUTS (men $40-$ 89 years), Austrian males

\begin{tabular}{|c|c|c|c|c|c|}
\hline & \multicolumn{2}{|l|}{1995} & \multicolumn{2}{|l|}{2009} & \multirow{2}{*}{$\begin{array}{l}\mathrm{p} \\
\text { value }\end{array}$} \\
\hline & median & $1-3 Q$ & median & $1-3 Q$ & \\
\hline Incomplete emptying & 0.0 & $0-1$ & 0.0 & $0-1$ & $<0.001$ \\
\hline Frequency & 1.0 & $0-2$ & 0.0 & $0-1$ & 0.001 \\
\hline Intermittency & 0.0 & $0-1$ & 0.0 & $0-1$ & 0.003 \\
\hline Urgency & 0.0 & $0-1$ & 0.0 & $0-1$ & 0.052 \\
\hline Weak stream & 0.0 & $0-1$ & 0.0 & $0-1$ & 0.003 \\
\hline Straining & 0.0 & $0-1$ & 0.0 & $0-0$ & $<0.001$ \\
\hline Nocturia & 1.0 & $0-2$ & 1.0 & $0-2$ & 0.980 \\
\hline IPSS score & 4.0 & $1-8$ & 3.0 & $1-7$ & 0.001 \\
\hline Voiding symptoms & 1.0 & $0-4$ & 0.0 & $0-3$ & $<0.001$ \\
\hline Storage symptoms & 2.0 & $1-5$ & 2.0 & $1-4$ & 0.046 \\
\hline Quality of life due to urinary symptoms & 1.0 & $0-2$ & 1.0 & $0-2$ & 0.254 \\
\hline Age, years & 56.0 & $48.0-64.0$ & 55.0 & $45.0-63.0$ & \\
\hline BMI & 26.0 & $24.1-28.4$ & 26.0 & $24.0-29.0$ & \\
\hline
\end{tabular}

$1-3 \mathrm{Q}=1$ st and 3rd quartiles. $\mathrm{p}$ values: Mann-Whitney $\mathrm{U}$ tests.

After categorization of single items into categories 'voiding symptoms' and 'storage symptoms', it can be shown that these categories improved statistically significantly (voiding symptoms: $\mathrm{p}<0.001$; storage symptoms: $\mathrm{p}=0.046)$.

The subanalysis of 10 -year age groups shows that the above-mentioned improvement of the total age group 4089 years is solely based on a statistically significant improvement in age group 50-59 years. The melioration in the other single age groups is visible, although statistically non-significantly throughout (data not shown).

Prevalence of Lower Urinary Tract Symptoms in Austrian Males
Table 4 also shows that the BMI of respondents deteriorated statistically significantly from a mean of 26.2 in the 1995 survey to a mean of 27.0 in 2009 ( $p=0.001$ ), and that age did not change between samples.

When categorizing men into respondents with 'mild' versus 'moderate-to-severe' symptoms (table 5), it can be shown that the percentage of respondents with 'mild' symptoms increased (from 83.1 to $86.6 \%$ ) while the fraction of respondents with 'moderate-to-severe' symptoms decreased (from 16.9 to $13.4 \%$ ) statistically significantly $(\mathrm{p}=0.036)$. Analysis of age groups reveals that there is a statistically nonsignificant melioration in age groups $50-$

Urol Int 2011;87:385-391 
Table 5. Comparison of the results in 1995 with the results in 2009 with regard to AUA score 'mild' (AUA score 0-7) and 'moderateto-severe' (score 8+) as well as quality of life 'dissatisfied' ('mostly dissatisfied' + 'unhappy' + 'terrible'), Austrian males 40-89 years, percentages (proportions of the total samples, $\chi^{2}$ tests)

\begin{tabular}{lrrl} 
& 1995 & 2009 & p values \\
\hline 'Mild' & 83.1 & 86.6 & 0.036 \\
'Moderate-to-severe' & 16.9 & 13.4 & 0.028 \\
Feel 'dissatisfied' & 9.1 & 6.3 & 0.028 \\
\hline
\end{tabular}

59 and $70+$ years and a statistically nonsignificant deterioration in age groups 40-49 and 60-69 years.

The prevalence of dissatisfaction with urinary symptoms meliorated statistically significantly $(\mathrm{p}=0.028)$. After collapsing the scores 4, 5 and 6 ('mostly dissatisfied', 'unhappy' and 'terrible') into one category, 9.1\% were dissatisfied in 1995 while $6.3 \%$ felt so in 2009 . This significant change again is caused solely by the change in the age group 50-59 years (data not shown).

\section{Discussion}

The advantages of our study are that we conducted two population-based cross-sectional studies using rather large samples each comprising $0.03 \%$ of the male population. However, there are also shortcomings: the IPSS measures the frequency of lower urinary tract symptoms which might be associated with $\mathrm{BPH}$ or other conditions, therefore our findings should not be misinterpreted as an evaluation of the prevalence of BPH in Austria. Furthermore, respondents were not assessed medically to detect co-morbidity or other possible causes for LUTS such as infections or diabetes mellitus. Moreover, the general quality of life measures have been shown to change after transurethral resection of the prostate $[9,10]$. We neither assessed if the respondents had ever sought medical advice because of urinary or prostate problems, nor if they underwent transurethral resection of the prostate or any other surgical treatment, nor if they took medication for treatment of urinary problems before or at the time of interview. Therefore, we cannot stratify our data for differences in IPSS between these groups. Regrettably, financial restraints prohibited the inclusion of these items into the questionnaire. The lack of information on these potential biasing factors makes the results difficult to interpret. It is unknown whether any bias exists in the drawn sample due to the selection method that had been applied by the public opinion institute. Nor is it known whether the results where biased by nonresponse of the men who were not at home at the time of the interview or who refused the interview. The overall response to the study of $96.3 \%$ is high, however, and should minimize a possible nonresponse bias.

The prevalence of LUTS has been studied in population-based surveys all over the world, and highly different results have been published [1, 11-17]. Prevalence of moderate-to-severe LUTS and median IPSS for Austrian men appeared to be closer to results for Olmsted County (USA) men, than to European countries (IPSS >7: 35.3\% in 1995 and $31.4 \%$ in 2009). Robert et al. [11] in 2010 published a prevalence of $16.8 \%$ of moderate-to-severe LUTS in a representative sample of French men. Lee et al. [18] found for the Korean EPIC study a prevalence of $53.7 \%$ in men increasing with age. The most recent study of Berges and Oelke [17] in a community-dwelling German population presents a continuing increase of IPSS with age, while the answer to the quality-of-life question (question 8) remains unchanged over the age groups.

We found a marked decrease in the prevalence of LUTS and in the severity of IPSS over a time period of 14 years in two cross-sectional studies, while Malmsten et al. [19] report an increase in the prevalence of LUTS from a longitudinal study over an 11-year period.

Elevated BMI may predispose to erectile dysfunction, but it has appeared to have no effect on LUTS [20]. In both our studies, we could not find a statistically significant correlation of BMI with IPSS. However, if age as an influencing factor is statistically not controlled for (correlation versus partial correlation) both times it would have been statistically significant.

The reasons for improvement of prevalence of LUTS in Austria remain unclear; however, we suppose a significant influence of opportunistic screening for prostate cancer by testing for PSA in Austria since the early 1990s, the prevalence of PSA screening in the target group men aged $40-79$ being $31.8 \%$ in a representative sample in $2005[3,4]$. This positive side effect of intensified physician contact resulting in the treatment of LUTS, however, is outweighed by the morbidization of the older male population by the uncritical usage of the PSA test $[5,7,8]$. Another possible explanation for the changes found is that in Austria the prescription of alpha blockers can be done by general practitioners and not only by urologists. So it may be easier for men to receive sufficient treatment for LUTS. 
In conclusion, the prevalence of LUTS in Austria declined statistically significantly between 1995 and 2009. This in part may be attributed to intensified contact of males with urologists due to opportunistic PSA screening as well as to the prescription of alpha blockers by general practitioners.

\section{Disclosure Statement}

The authors have no conflicts of interest to declare.

\section{References}

1 Haidinger G, Madersbacher S, Waldhoer T, Lunglmayr G, Vutuc C: The prevalence of lower urinary tract symptoms in Austrian males and associations with sociodemographic variables. Eur J Epidemiol 1999;15: 717-722.

$\checkmark 2$ Vutuc C, Waldhoer T, Madersbacher S, Micksche M, Haidinger G: Prostate cancer in Austria: impact of prostate-specific antigen test on incidence and mortality. Eur J Cancer Prev 2001;10:425-428.

$\checkmark 3$ Vutuc C, Schernhammer ES, Haidinger G, Waldhör T: Prostate cancer and prostate specific antigen (PSA) screening in Austria. Wien Klin Wochenschr 2005;117:457-461.

$\checkmark 4$ Vutuc C, Waldhoer T, Sevelda P, Micksche M, Haidinger G: Self-reported prostate cancer screening in Austria. J Med Screen 2006; 13:148-151.

5 Haidinger G, Madersbacher S, Schatzl G, Vutuc C: Radical prostatectomies in Austria, 1997-2004. BMC Res Notes 2008;1:48.

6 Statistics Austria (ed): Bevölkerungsstand 1.1.2009. Vienna, Verlag Österreich, 2009.

7 Vutuc C, Waldhoer T, Lunglmayr G, Hoeltl W, Haidinger G: PSA testing in Austria: induced morbidity and saved mortality. Eur J Cancer Prev 2009; 18:377-380.

$\checkmark 8$ Madersbacher S, Vutuc C: Prostatakarzinom-Screening: Sinn oder Unsinn. Wien Klin Wochenschr 2009;121:428-430.
-9 Fowler FJ, Wennberg JE, Timothy RP, Barry MJ, Mulley AG, Hanley D: Symptom status and quality of life following prostatectomy. JAMA 1988;259:3018-3022.

10 Fowler FJ: Patient reports of symptoms and quality of life following prostate surgery. Eur Urol 1991;20(suppl 2):44-49.

11 Robert G, Descazeaud A, Azzouzi R, Saussine C, Haillot O, Dumonceau O, Ballereau C, Fourmarier M, Devonec M, Lukacs B, Delongchamps NB, Desgrandchamps F, de la Taille A: Impact of lower urinary tract symptoms on discomfort in men aged between 50 and 80 years. Urol Int 2010;84:424-429.

12 Garraway WM, Collins GN, Lee RJ: High prevalence of benign prostatic hypertrophy in the community. Lancet 1991;338:469-471.

13 Sagnier PP, MacFarlane G, Richard F, Botto $\mathrm{H}$, Teillac P, Boyle P: Results of an epidemiological survey using a modified American Urological Association symptom index for benign prostatic hyperplasia in France. J Urol 1994;151:1266-1270.

14 Hunter DJ, Berra-Unamuno A, Martin-Gordo A: Prevalence of urinary symptoms and other urological conditions in Spanish men 50 years old or older. J Urol 1996;155:19651970.

15 Norman RW, Nickel JC, Fish D, Pickett SN: 'Prostate-related symptoms' in Canadian men 50 years of age or older: prevalence and relationships among symptoms. Br J Urol 1994;74:542-550.
16 Bosch JL, Hop WC, Kirkels WJ, Schroder FH: The International Prostate Symptom Score in a community-based sample of men between 55 and 74 years of age: prevalence and correlation of symptoms with age, prostate volume, flow rate and residual urine volume. Br J Urol 1995;75:622-630.

17 Berges R, Oelke M: Age-stratified normal values for prostate volume, PSA, maximum urinary flow rate, IPSS, and other LUTS/ $\mathrm{BPH}$ indicators in the German male community-dwelling population aged 50 years or older. World J Urol 2011;29:171-178.

18 Lee YS, Lee KS, Jung JH, Han DH, Oh SJ, Seo JT, Lee JG, Park HS, Choo MS: Prevalence of overactive bladder, urinary incontinence and lower urinary tract symptoms: results of Korean EPIC study. World J Urol 2011;29: 185-190.

19 Malmsten UGH, Molander U, Peeker R, Irwin DE, Milsom I: Urinary incontinence, overactive bladder, and other lower urinary tract symptoms: a longitudinal populationbased survey in men aged $45-103$ years. Eur Urol 2010;58:149-156.

20 Bhojani N, Perrotte P, Hutterer G, Suardi N, Jeldres C, Shariat SF, Capitanio U, Arjane P, Widmer H, Benard F, Peloquin F, Montorsi F, Karakiewicz P: Body mass index and its association with genitourinary disorders in men undergoing prostate cancer screening. J Sex Med 2008;5:2141-2151. 